Abstracta Iranica Abstracta Iranica

Revue bibliographique pour le domaine irano-aryen

Volume 22 | 2001

Comptes rendus des publications de 1999

Grundzüge der Vor- und Frühgeschichte Irans. Die Arier in den nahöstlichen Quellen des 3. und 2. Jahrtausends v. Chr. Tehran, International Publications of Iranian Studies, 1998, VII + 308 p.

Philip Huyse

\title{
OpenEdition
}

Journals

Édition électronique

URL : http://journals.openedition.org/abstractairanica/37479

DOI : 10.4000/abstractairanica.37479

ISSN : 1961-960X

Éditeur :

CNRS (UMR 7528 Mondes iraniens et indiens), Éditions de l'IFRI

Édition imprimée

Date de publication : 15 mai 2001

ISSN : 0240-8910

Référence électronique

Philip Huyse, «Grundzüge der Vor- und Frühgeschichte Irans. Die Arier in den nahöstlichen Quellen des 3. und 2. Jahrtausends v. Chr. Tehran, International Publications of Iranian Studies, 1998, VII + 308 p. », Abstracta Iranica [En ligne], Volume 22 | 2001, document 81, mis en ligne le 15 février 2010, consulté le 13 octobre 2020. URL : http://journals.openedition.org/abstractairanica/37479 ; DOI : https://doi.org/ 10.4000/abstractairanica.37479

Ce document a été généré automatiquement le 13 octobre 2020

Tous droits réservés 


\section{Grundzüge der Vor- und Frühgeschichte Irans. Die Arier in den nahöstlichen Quellen des 3. und 2. Jahrtausends v. Chr. Tehran, International Publications of Iranian Studies, 1998, VII + 308 p.}

Philip Huyse

1 Il arrive de temps en temps que surgissent, ex nihilo ou presque, des hypothèses spectaculaires mettant en cause les théories établies et acceptées par la majeure partie de la communauté scientifique. Tel est le cas ici et l'on imagine bien la méfiance des traditionalistes à l'égard des idées osées par lesquelles l'auteur explique la présence précoce des Aryens dans le Proche et le Moyen-Orient. L'ouvrage achevé comprendra trois volumes, dont le premier est divisé en deux cahiers. Le premier de ces cahiers est maintenant publié (1995), le deuxième devrait paraître sous peu et est préparé par le deuxième livre recensé ici (1998).

Dans le premier demi-cahier du premier volume, l'auteur tente de situer dans le temps le prophète Zarathuštra, vers 1800 av. J.-C. Il rejette à juste titre la thèse ancienne dite "de Vištāspa », selon laquelle kavi Vištāspa, le protecteur du prophète dans les Gā̄līâas, serait à identifier avec le père de Darius Ier; en revanche, on aimerait obtenir un peu plus d'arguments pour la date assez haute avancée pour Zarathuštra. Une conséquence de cette date est que, pour l'auteur, la dynastie des Kayanides sort du légendaire. Mais certains des arguments sont contestables ou faux : p. ex., les inscriptions vieux-perses attribuées à Arsamès et Ariaramnès sont à l'évidence des faux du $4 \mathrm{e}$ s. av. J.-C. et ne peuvent donc fournir aucune information sur la religion des Achéménides avant Cyrus II (pp. 74-76). 
3 Mais c'est le deuxième livre qui est certainement le plus « choquant " par la témérité et les conséquences des thèses avancées. Selon l'auteur, les Aryens auraient été présents sur le plateau iranien dès le $3 \mathrm{e}$, voire le $4 \mathrm{e}$ millénaire, d'où ils se seraient répandus; et l'indo-iranien ne serait pas issu de l'indo-européen commun, mais le développement se serait produit dans la direction inverse. Cette brève notice n'est pas l'endroit idéal pour une argumentation détaillée, mais dans le raisonnement de l'auteur la chronologie relative des changements phonologiques me semble souvent subordonnée à la ressemblance apparente des mots.

4 En conclusion, j'espère pourtant avec l'auteur que ses thèses à la fois originales et gênantes ne seront pas simplement négligées, mais que l'on cherchera la voie de la critique constructive. Je reste toutefois très sceptique quant au succès, car l'impression finale est un peu celle d'une pêche avec un filet dont les mailles sont trop larges. Mais comme l'auteur promet plus de preuves dans les volumes à venir, il faudrait tout de même attendre sa démonstration complète. [Ce compte rendu concerne également le $\mathrm{n}^{\circ}$ 80]

INDEX

Thèmes : 3.0. Généralités

\section{AUTEURS}

PHILIP HUYSE

CNRS - Paris 